\title{
ESTUDO SOBRE A APRENDIZAGEM DE CÁLCULO I NOS CURSOS DE ENGENHARIA DO CENTRO UNIVERSITÁRIO SANTO AGOSTINHO - UNIFSA ${ }^{1}$
}

\author{
Nemone de Sousa Pessoa (UNIFSA) ${ }^{2}$ \\ Karmem Weruska Fortes Araujo (UNIFSA) ${ }^{3}$ \\ Geraldino de Sousa ( UNIFSA) ${ }^{4}$
}

\begin{abstract}
RESUMO
A aprendizagem do Cálculo Diferencial e Integral I nos cursos de Engenharia tem sido motivo de discussões diversas no contexto educacional de ensino superior, dada a dificuldade verificada pelos estudantes desses cursos ao longo da proposta pedagógica trazida com o ensino dessa disciplina. Tais dificuldades se ajustam aos altos índices de reprovação observados, sendo condicionante, em muitos casos, para a desistência de estudantes no decorrer de seu processo educativo no curso. Assim, esse estudo tem como objetivo investigar algumas variáveis que podem ser fatores geradores para o baixo desempenho de estudantes nessa disciplina, de forma a subsidiar o trabalho pedagógico dos professores nos cursos de área exata e outras. Essa pesquisa configura-se como quantitativa e qualitativa, aplicada, exploratória e de campo. A população corresponde a estudantes dos cursos de engenharia selecionados a partir de uma amostragem probabilística aleatória simples nos cursos de Engenharias Civil, Elétrica e de Produção do UNIFSA que já cursaram a disciplina de Cálculo I. A pesquisa bibliográfica foi realizada com base em autores como Malta (2004), Rezende (2003) e Silva (2009), entre outros, além de consulta a dados da Sinopse Estatística da Educação Superior (2017) coordenada pelo INEP/Ministério da Educação. Os resultados obtidos indicam que os estudantes consideram a falta de conhecimentos matemáticos básicos como um dos fatores que interferem na aprendizagem da disciplina, observando também que os mesmos não possuem uma rotina de estudos sistemática para a disciplina.
\end{abstract}

Palavras-Chave: Rendimento de alunos. Reprovação Cálculo I. Engenharia. Unifsa.

\section{INTRODUÇÃO}

No contexto educacional atual, a preocupação com o ensino e a aprendizagem de alunos tem se tornado fator de discussão acadêmica, tanto nos níveis básico como

\footnotetext{
1 Trabalho apresentado no Congresso Brasileiro Ciência e Sociedade (CBCS 2019), promovido pelo Centro Universitário Santo Agostinho, de 03 a 05 de outubro de 2019, em Teresina-PI.

${ }^{2}$ Mestra em Educação, Graduada em Matemática, docente dos cursos de Engenharias Civil, Elétrica e de Produção do Centro Universitário Santo Agostinho - UNIFSA, nemoneli@msn.com.

${ }^{3}$ Mestra em Engenharia de Produção, Graduada em Matemática, docente dos cursos de Engenharias Civil, Elétrica e de Produção do Centro Universitário Santo Agostinho - UNIFSA, kwfa35@ gmail.com.

${ }^{4}$ Especialista em Matemática, Graduado em Matemática, docente dos cursos de Engenharias Civil, Elétrica e de Produção do Centro Universitário Santo Agostinho - UNIFSA., geraldinosousa@ gmail.com.
} 


\section{congeESSOC CIENCIAESOCIEDADE

superior. Discussões mais contumazes em educação são acondicionadas principalmente nas disciplinas que envolvem a área de exatas e/ou cursos dessa área.

As disciplinas que exigem conhecimentos da Matemática são aquelas que estão no ápice de tais discussões, isso porque a Matemática é abstrata e necessita de conhecimentos prévios.

Nos cursos superiores, muitos alunos chegam com defasagem em conhecimentos matemáticos básicos. Consoante Malta (2004), as discussões nesse âmbito convergem para as disciplinas básicas dos cursos de exatas. Pode-se afirmar, "baseando-se na comunicação informal que ocorria, entre professores de nossas universidades, que a atenção para essa questão foi provocada pelo crescente índice de reprovação nas disciplinas básicas, em especial as disciplinas de Cálculo" (MALTA, 2004, p. 41).

De acordo com o autor, e o que tradicionalmente se verifica, é que estas disciplinas apresentam um alto índice de alunos reprovados. As reprovações podem estar relacionadas à metodologia utilizada pelos professores da disciplina, que ministram o conteúdo sem a preocupação com aprendizagem dos alunos, ou ainda, pela formação básica deficiente na Matemática do ensino fundamental e médio dos estudantes que, posteriormente, ingressam nesses cursos.

Conforme Soares e Sauer (2004), as dificuldades relacionadas à Matemática, o alto índice de reprovação dos alunos em disciplinas dessa área, bem como as dificuldades de engenheiros em lidar com os conceitos matemáticos na vida profissional, são algumas variáveis que indicam a necessidade de examinar questões relacionadas ao tema "ensino-aprendizagem da matemática para a engenharia".

A partir de tais argumentações e considerando o número alto de reprovações dos estudantes na disciplina de Cálculo Diferencial e Integral (Cálculo I) dos cursos de Engenharia do UNIFSA - Centro Universitário Santo Agostinho, em Teresina, PI, propôs-se investigar o motivo pelo qual os alunos que se preparam para serem futuros engenheiros, apresentam dificuldades nesta disciplina, sendo esta muito temida pelos alunos da graduação. 


\section{cONGGESSOCIENCIAESOCIEDADE

Assim, além de analisar as dificuldades dos alunos, é proposto também verificar se o problema está intimamente ligado ao histórico escolar do mesmo, se a metodologia utilizada pelo professor é condizente com o contexto social e o desenvolvimento cognitivo desses estudantes ou ao embasamento matemático trazido pelos mesmos. A incumbência deste estudo traz como função a análise de variáveis pedagógicas que possam colaborar para a melhoria da aprendizagem dos estudantes de Engenharia, público alvo dessa pesquisa, na disciplina básica de Cálculo I, ofertada no primeiro período dos cursos. O objetivo é tentar diminuir o número de reprovações na disciplina, ou ainda, evitar desistências no Curso. Do ponto de vista local, os dados coletados nessa pesquisa servirão de base para a potencialização da prática pedagógica dos professores da Instituição na melhoria da qualidade do ensino dos conteúdos além de ser uma iniciativa pioneira na IES.

\section{METODOLOGIA}

Essa pesquisa explicativa, cujo campo de ação respalda-se no processo de ensino e aprendizagem de Cálculo I nos cursos de Engenharia do UNIFSA e tendo como público alvo docentes e discentes dos cursos das Engenharias Civil, Elétrica e de Produção, foi desenvolvida com base em uma abordagem qualitativa e quantitativa, de natureza básica, descritiva e de campo, o que respaldará uma melhor compreensão no contexto em que ocorre.

Para a coleta de dados, além da pesquisa bibliográfica, será realizada uma pesquisa de campo com o intuito de obter conhecimento da realidade educacional e a interação com os sujeitos e a instituiçãoinvestigada.

A pesquisa de campo foi mediada a partir da aplicação de um questionário composto de 10 (dez) questões objetivas aos estudantes do 2 a e 3 o períodos que cursaram a disciplina de Cálculo I distribuídas nos três cursos de Engenharia do UNIFSA até o primeiro semestre de 2018. As questões desse questionário estão relacionadas à afinidade dos alunos com a disciplina, sua formação no ensino básico, o nível de 


\section{CONGGESSOCIENCIAESOCIEDADE \\ Inovação, Diversidaaile e Sustentahilitiladie}

participação do aluno durante as aulas da disciplina em sala de aula ou fora dela; os fatores que eles julgam terem contribuído para o baixo rendimento na disciplina e a relação professor-aluno que se desenvolve em sala, a partir de uma perspectiva subjetiva. A amostra, nessa pesquisa, foi composta por 79 (setenta e nove) estudantes, sendo usado o critério probabilístico aleatório simples.

O questionário seguindo o método científico foi aplicado nas dependências da IES e preservou o anonimato dos participantes de forma que eles possam expor suas dificuldades e opiniões sem qualquer tipo de constrangimento, sendo submetido aos estudantes dos três cursos de Engenharia, por meio de Software de perguntas e respostas, denominado Socrative. O Socrative é um aplicativo de sala de aula para auxiliar o professor na aplicação de atividades acadêmicas por meio de testes e quizes. Uma das vantagens do uso deste aplicativo é que as respostas dadas aos testes são processadas automaticamente, de forma que ao final da aplicação o mediador possua os resultados da atividade em tempo real, através de um relatório que pode ser gerado pela ferramenta.

As respostas obtidas nos questionários foram convertidas em análises numéricas, valendo-se da estatística descritiva, conforme discutiremos a seguir.

\section{ASPECTOS SÓCIO HISTÓRICOS DO UNIFSA}

A Faculdade Santo Agostinho iniciou suas atividades em 1998, tendo sua sede situada na Rua Telegrafista Sebastião Portela, no 3.587, Bairro São João. Em 2003, para consolidar a sua proposta de oferta de ensino de qualidade, a Faculdade adquiriu novo espaço, situado na Avenida Valter Alencar no 665, Bairro São Pedro, agregando todos os cursos da Instituição.

Mais recentemente, em 2018, a Faculdade Santo Agostinho alcançou o status de Centro Universitário - UNIFSA, o que a consolida no mercado educacional do Estado, sendo referência em ensino, inclusive em estados vizinhos, como o Maranhão, do qual inclusive, recebe a cada vestibular, uma grande quantidade de estudantes. 


\section{CONGEESSOOCIENCIAESOCIEDADE

Os cursos de graduação ofertados se consolidam nas áreas de Humanas, Saúde e Engenharias, dos quais destacamos: Direito, Enfermagem, Odontologia, Fisioterapia, Administração, Pedagogia, Arquitetura, Serviço Social, entre outros, além das Engenharias Civil, Elétrica e de Produção, que se constituem objeto de nossa pesquisa.

Além dos cursos de graduação a Instituição ainda conta com cursos de pósgraduação nas áreas de Direito, Saúde, Tecnologia e Pedagogia, além de cursos na área tecnóloga.

O município de Teresina, local onde fica situada a Faculdade Santo Agostinho é a 19a maior cidade do Brasil com uma população estimada em 2019, segundo o IBGE, de 864.845 habitantes. Tal população ocupa área de 1.392 km² (IBGE, 2013). Constituise também o principal centro de referência do aglomerado metropolitano de um conjunto de 15 cidades que, juntas, configuram a "Região Integrada de Desenvolvimento da Grande Teresina" - RIDE, criada pela Lei Complementar n.o 112, de 19/09/2001, com o objetivo de articular as ações do poderpúblico.

No tocante à área educacional, Teresina tem se destacado nos níveis de ensino fundamental, médio e superior, o que tem contribuído significativamente para uma grande procura, principalmente por pessoas do interior do Estado do Piauí e até mesmo de outros estados.

$\mathrm{Na}$ Educação Superior, o Estado do Piauí, conta com duas universidades públicas, a Universidade Federal do Piauí e a Universidade Estadual do Piauí, espalhadas em vários campi no Estado. Ainda em nível superior, possui o Instituto Federal de Educação Ciências e Tecnologias e 41 instituições de ensino superior privadas, conforme dados do Censo da Educação Superior (2017,MEC/INEP).

Segundo a mesma fonte, as matrículas nestas instituições chegaram em 2017 a 127.257 (cento e vinte e sete mil e duzentos e cinquenta e sete) estudantes, sendo que as instituições de ensino superior contemplam $56,3 \%$ do total de matriculas do estado, quase 72 mil estudantes. 


\section{ASPECTOS SÓCIO EDUCACIONAIS DOS CURSOS DE ENGENHARIA}

A formação nos cursos de engenharia do UNIFSA justifica-se no contexto sócioeducacional e econômico do país em decorrência da demanda atual destes profissionais no mercado de trabalho.

Em âmbito nacional, a concretização de parte das obras do Programa de Aceleração do Crescimento (PAC), do Pré-Sal e os investimentos realizados em infraestrutura para a Copa do Mundo 2014 e as Olimpíadas 2016, o Brasil, inevitavelmente, defrontou-se com um aumento da demanda por profissionais altamente qualificados, de tal forma que a definição desses investimentos desempenha uma função importante na demarcação das necessidades futuras de formação e qualificação profissional. Os investimentos também destinados aos programas de eficiência energética, principlamente com o que se denomina "energia limpa" fez com que os cursos de engenharia elétrica se tornassem muito procurados em nível superior.

Projeções realizadas por especialistas, em 2014, revelam que, em termos agregados, o uso de engenheiros em todo o Brasil deve aumentar em média 3,76\% a.a., o que representa um crescimento de $49,22 \%$ entre 2012 e 2023 , elevando o uso de engenheiros de 228.582 trabalhadores em 2012 para 341.080 em 2023. Esse mesmo estudo, evidencia que o Piauí nesse mesmo período deverá elevar em 35\% o número de engenheiros empregados. (SOUZA; DOMINGUES, 2014)

Nesse contexto de profundas mudanças, os cursos de bacharelado em Engenharia do Centro Universitário Santo Agostinho assumem o compromisso de dotar a região de mão de obra qualificada, resultando em desdobramentos relevantes que contribuem para o desenvolvimento cultural, científico e profissional, considerando, ainda, o déficit de profissionais engenheiros para atender à demanda local, a qual se alinha em uma problemática de nível nacional.

Em âmbito local, 15 instituições de Ensino superior oferecem cursos de engenharia civil, sendo 2 em instituições públicas e 13 em privadas. Já os cursos de Engenharia de Produção são ofertados em 8 instituições privadas e apenas 1 pública; a Engenharia Elétrica é ofertada em 6 privadas e 02 públicas. 


\section{ASPECTOS COGNITIVOS EXIGIDOS NA DISCIPLINA DE CÁLCULO I}

Os problemas decorrentes do ensino de Cálculo I no primeiro semestre das faculdades e universidades, nas diferentes áreas do conhecimento como Engenharias, Matemática, Física, Química, Economia, Administração etc., vêm sendo objeto de estudo de muitos pesquisadores em Educação Matemática. "É bastante comum que, nesses cursos, a disciplina de Cálculo I apresente altos índices de reprovação e desistência" Rezende (2003). Nesse sentido, (SILVA, 2009) nos afirma que "o desempenho insatisfatório dos alunos nessa disciplina tem preocupado pesquisadores de todo o mundo, com níveis altíssimos de reprovação e desistências em cursos de Licenciaturas e Engenharias".

A análise do plano de ensino da disciplina de Cálculo I do UNIFSA, onde se desenvolveu a pesquisa justifica a inserção da disciplina no programa do curso quando observamos o plano de ensino e buscamos o objetivo geral para o ensino de Cálculo I

Possibilitar aos estudantes a compreensão das técnicas do Cálculo Diferencial e Integral para funções reais de uma variável real, dando ênfase às suas aplicações com vistas à resolução de problemas com utilização de novas tecnologias, em atendimento às demandas da sociedade (Plano de Ensino, Cálculo Diferencial e Integral I, p.1).

Nessa perspectiva, é preciso dotar os futuros engenheiros de competências matemáticas básicas que o auxiliem na apropriação de conhecimentos específicos que a profissão exige. Já a ementa da disciplina, prevê o estudo de Limites e Derivadas de funções de uma variável real, bem como as primeiras técnicas de Integração para resolução de integrais indefinidas e definidas, com aplicações em problemas de otimização cálculo de áreas.

A leitura de pesquisas relacionadas ao ensino de Cálculo chama a atenção para o fato de que, para além das dificuldades em compreender os conceitos relativos ao Cálculo Diferencial, reside também uma preocupação em verificar quais são os recursos metodológicos que o professor usa em suas aulas e como esses recursos interferem no resultado ao longo do processo de ensino e de aprendizagem. A certeza da importância de se oferecer recursos variados como estratégia para solucionaras 
difuldades apresentadas pelos estudantes na disciplina de Cálculo I é ratificada por Bianchini ; Puga (2006), que constataram que nem sempre a relação entre as diversas formas de representar uma função (algébrica e gráfica) é de domínio dos alunos, ou seja, as pesquisadoras perceberam que os alunos não conseguem, na maioria dos casos, coordenar essas duas formas de representação, por exemplo.

Algumas hipóteses são consideradas para as eventuais dificuldades dos alunos em relação aos conteúdos do Cálculo Diferencial e Integral I, uma delas é notória entre os professores que ministram esta disiciplina. Uma boa parte dos alunos chega ao curso de Engenharia sem a devida consolidação de uma base de conhecimentos matemáticos, apresentando dificuldade em resolução de equações, por exemplo, ou ainda dificuldades de compreensão das propriedades de potenciação e radiciação. $A$ construção de gráficos também é outra dificuldade constante em boa parte dos estudantes, bem como o uso de processos indutivos para apresentar estratégias de resolução de problemas algébricos e geométricos.

Outra hipótese levantada é que a educação básica recebida pelos estudantes, notadamente, oriundos de escola pública no UNIFSA, não preenche na sua totalidade as competências que tais alunos deveriam ter para ingresso no ensino superior.

O alto índice de reprovação identificado nesta disciplina, que é ofertada nos primeiros períodos dos cursos de Engenharia, levanta outra hipótese que está relacionada a metodologia do professor, pois eventualmente não possui traços semelhantes com àquela a qual o estudante de ensino médio tenha sido submetido em época anterior. Fazendo-os repensar a prática e implementar estratégias que possam favorecer uma aprendizagem significativa para os ingressantes nos cursos de Engenharia e que levem a menos reprovações.

\section{REPROVAÇÕES EM CÁLCULO I NOS CURSOS DE ENGENHARIA DA UNIFSA}

As informações a seguir foram retiradas do sistema Academus da UNIFSA, que consolida as informações de matrícula, frequencia, notas, aprovação e reprovação dos estudantes de todos os cursos oferados pela IES, incluindo-se os de Engenharia. De 


\section{CONGEFESSOCIENCIAESOCIEDADE

início, levaremos em consideração a análise dos dados de matrícula e o total de reprovações na disciplina de Cálculo I nos cursos de Engenharia Civil, Elétrica e de Produção, nos anos de 2016 e 2017.

Tabela 1 - Matrícula de estudantes de Engenharia no Cálculo I

\begin{tabular}{l|llll}
\multicolumn{1}{l}{ Cursos } & 2016.1 & 2016.2 & 2017.1 & 2017.2 \\
\hline Civil & 152 & 84 & 107 & 89 \\
Elétrica & 45 & 14 & 24 & 16 \\
Produção & 37 & 32 & 41 & 0 \\
TOTAL & $\mathbf{2 3 4}$ & $\mathbf{1 3 0}$ & $\mathbf{1 7 2}$ & $\mathbf{1 0 5}$
\end{tabular}

Fonte: Sistema Academus (2018)

Tabela 2 - Reprovação por Nota de estudantes de Engenharia no Cálculo I

\begin{tabular}{l|llll}
\multicolumn{1}{l}{ Cursos } & 2016.1 & 2016.2 & 2017.1 & 2017.2 \\
\hline Civil & 70 & 35 & 40 & 26 \\
Elétrica & 18 & 2 & 2 & 5 \\
Produção & 15 & 6 & 10 & 0 \\
TOTAL & $\mathbf{1 0 3}$ & $\mathbf{4 3}$ & $\mathbf{5 2}$ & $\mathbf{3 1}$
\end{tabular}

Fonte: Sistema Academus (2018)

A Tabela 1, revela que a matrícula de alunos em Cálculo 1 no 1을 semestre é relativamente maior em relação às do 20 semestre na mesma disciplina. 0 curso de Engenharia Civil é dos três o que mais matriculou no período analisado, representando perto de $65 \%$ em 2016.1 e 2016.2, 62\% em 2017.1 e 85\% em 2017.2. Já a Tabela 2 mostra que o número de reprovados diminuiu ao longo do período analisado.

Uma análise percentual da reprovação, nessa situação, potencializa o estudo estatístico a que se destina essa pesquisa. Para tal, no entanto, deve-se levar em consideração nesse cálculo o número de alunos que frequentaram às aulas até o final do período (alunos frequentes), que, nesse caso, se difere do número de matrículas na mesma disciplina. 


\section{CONGGESSOCIENCIAESOCIEDADE \\ Inovação, Diversidatle e Sustentabilitilatie}

Tabela 3 - Percentual de Alunos reprovados em Cálculo I

\begin{tabular}{l|llll}
\multicolumn{1}{l}{ Cursos } & 2016.1 & 2016.2 & 2017.1 & 2017.2 \\
\hline Civil & 49,3 & 50 & 42,1 & 32,9 \\
Elétrica & 41,8 & 16,7 & 10,0 & 38,5 \\
Produção & 53,6 & 26,0 & 32,2 & 0 \\
MÉDIA & $\mathbf{4 8 , 2}$ & $\mathbf{3 1 , 0}$ & $\mathbf{2 8 , 1}$ & $\mathbf{3 5 , 7}$
\end{tabular}

Fonte: Sistema Academus (2018)

Com base na Tabela 3, o índice de reprovação, embora numa curva decrescente ainda apresente em média índices de reprovação da ordem de $30 \%$ nos três cursos de Engenharia. O que pode ser considerado, do ponto de vista cognitivo, um índice relativamente alto de não aprendizagem.

\section{ANÁLISE DOS RESULTADOS}

Com base nas respostas aos questionários, evidenciamos alguns aspectos que poderiam traçar o perfil do aluno das Engenharias no UNIFSA, bem como algumas evidências que poderiam esboçar o desempenho dos estudantes na disciplina de Cálculo I.

Com relação aos ingressantes desses cursos, foi possível verificar que, em sua maioria, 49,4\%, cursaram a maior parte do Ensino Médio em escola pública da rede estadual, $40,3 \%$ em escolas privadas e apenas 10,4\% em instituições federais. Sendo que $63,3 \%$ ingressaram no ensino superior menos de 2 anos após a conclusão do Ensino Médio. Nesse ponto, 13,9\% ingressaram na IES com mais de 5 anos de diferença ao tempo em que eram estudantes secundaristas.

Quanto ao desempenho dos alunos na disciplina verificou-se que 70,9\% dos entrevistados cursaram a disciplina uma única vez, $25,3 \%$ ou 20 estudantes duas vezes, e 3,8\% três vezes ou mais. Sendo que a percepção inicial destes sobre a disciplina em relação ao nível de complexidade foi muito difícil (31,6\%); 62\% tiveram dificuldade 
intermediária para compreensão dos conteúdos e, apenas, 6,3\% consideraram a disciplina de fácil entendimento.

Essa percepção inicial sobre a disciplina é corroborada pelas respostas de $55,1 \%$ dos estudantes, quando perguntados sobre tal situação, responderam "Dificuldade de compreensão dos conceitos matemáticos apresentados, pois não tive uma base sólida desses conhecimentos no Ensino Médio"; 19,2\% ou 15 estudantes disseram que "Embora eu não tivesse muita base dos conceitos matemáticos apresentados na disciplina, a metodologia utilizada pelo professor em sala de aula facilitou o meu entendimento"; apenas 6,4\% disseram que "A metodologia utilizada pelo professor em sala de aula dificultou o meu entendimento"; outros 1,3\% não "possuíam afinidade com a área de exatas" e, por isso, não tiveram bom desempenho na disciplina.

Com relação a rotina de estudos desses estudantes para a disciplina de Cálculo I, 58,2\% estabeleceram uma rotina de estudos semanal; 25,3\% estudavam às vésperas da avaliação de aprendizagem; 15,2\% diariamente e 1 aluno afirmou que nunca estudava. Outro aspecto analisado, diz respeito as estratégias utilizadas pelos estudantes para sanar eventuais dúvidas de conteúdos e conceitos desta disciplina. Em sua grande maioria, 59,2\% buscavam apoio em livros e vídeo aulas, 25\% procuravam ajuda junto aos colegas da turma; 13,2 \% ou 10 alunos procuravam apoio no professor da disciplina e, não houve registro de auxílio junto ao programa de monitoria da instituição.

A última pergunta do questionário disponibilizado para os alunos investiga se uma posição mais ativa do aluno no processo de aprendizagem poderia ser um aspecto positivo a ser considerado pelo professor na metodologia utilizada para a disciplina de Cálculo I. Assim, os alunos foram indagados se participariam de uma proposta de metodologia para o ensino da disciplina denominada "sala de aula invertida" na qual o aluno recebe o conteúdo antecipadamente para estudar e fazer exercícios sem o auxílio do professor. Posteriormente, em um ou dois encontros presenciais o professor examina o quanto o aluno se aprofundou nessas leituras antecipadas e, só então, esclarece as dúvidas e/ou complementa toda a parte teórica. 
As respostas obtidas dão conta de que $70,1 \%$ participariam dessa metodologia pouco usual. Os demais, 29,9\%, portanto, discordam dessa proposta.

\section{CONSIDERAÇÕES FINAIS}

Primeiramente, seria notório inferir que as dificuldades de aprendizagem notadamente discutidas até o presente momento, não se tratam de uma problemática observada apenas entre os cursos de Engenharia do UNIFSA. Na realidade, estudos acadêmicos realizados ao longo dos últimos anos nessa área evidenciam um problema generalizado entre as instituições de ensino superior em todo o território nacional, nos âmbitos dos cursos da área de exatas e/ou outras.

A importância ao se abordar esta situação no UNIFSA tem como aspecto central uma preocupação evidenciada pelos professores e coordenadores de curso com os altos índices de reprovação que disciplina, a cada semestre, apresenta, fazendo-nos analisar possíveis causas ou variáveis relacionadas a tais questões.

Nessa perspectiva, algumas hipóteses levantadas anteriormente serão, a partir de agora, rechaçadas ou justificadas, mediante as respostas dadas ao questionário aos quais os estudantes dos cursos foram submetidos.

De fato, a maioria dos estudantes dos cursos de Engenharia do UNIFSA cursou o ensino médio em escola pública da rede estadual, sendo este uma característica que justificaria um rendimento não muito satisfatório na disciplina de Cálculo I, tendo em vista ser a educação ofertada no ensino público, constantemente referenciada pelo baixo desempenho dos estudantes, altas taxas de reprovação e abandono escolar. Entretanto, vale ressaltar que também é observado na amostra de estudantes questionados, um percentual relativamente próximo de estudantes que cursaram o ensino médio em escolas privadas. Assim, podemos até pressupor que o fato de ser estudante de escola pública pode atravancar o fluxo quando do seu ingresso em cursos superiores. Contudo, não se pode inferir que tal aspecto trata-se de um condicionante para o seu bom desempenho acadêmico, já que muitos estudantes oriundos de escola particular também apresentaram as mesmas dificuldades que àqueles. 
Essa argumentação pode ser consolidada com a evidência de que mais da metade dos estudantes da amostra indicaram que não trouxeram do ensino médio uma base de conhecimentos matemáticos que os fizessem compreender de forma eficiente os conceitos e conteúdos abordados na disciplina de Cálculo I. Apenas, uma pequena parcela desses estudantes questionou sobre a metodologia utilizada pelo professor caracterizando-a como um fator que melhor aproveitamento acadêmico na disciplina.

Com relação às responsabilidades do estudante no seu próprio aprendizado e, consequente, desempenho na disciplina, observou-se que a grande maioria prefere sanar as dúvidas em momentos posteriores às aulas, utilizando principalmente recursos de vídeos aulas ou livros. A figura do professor como um recurso de apoio e auxilio durante as aulas, pode estar implicada ainda a uma condição do estudante que, por timidez ou medo, prefere não questionar o professor para sanar eventuais dúvidas.

A rotina de estudos da disciplina é organizada por cerca de $60 \%$ dos estudantes em períodos semanais, conforme resposta dada ao questionário; o que nos leva a concluir, que o fato de a disciplina ser ofertada no UNIFSA, duas vezes por semana, levou a maioria dos estudantes a responderem que a estudam semanalmente, não considerando que uma rotina de estudos é estabelecida em momentos anteriores ou posteriores a aula, e não nos momentos em que estas acontecem; um quarto da amostra confirmou que estudavam as vésperas das avaliações para a disciplina de Cálculo I.

Um resultado observado nas respostas dadas pelos estudantes da amostra e, supostamente inusitadas para a maioria dos docentes desta disciplina ditos "tradicionais", diz respeito ao uso de metodologias ativas, e mais especificamente, a sala de aula invertida, que amplia significativamente a autonomia, participação e coreponsabilização do estudante pelo seu aprendizado; levando-nos a perceber outras possibilidades de aprendizagem que não sejam demasiadamente previsíveis, mas que, sobretudo possam agregar valores outros que, não apenas, os cognitivos/conteudistas. 


\section{cONGQBESO CIENCIAESOCIEDADE

REFERÊNCIAS

BIANCHINI, B., \& PUGA, L. Z. (2006). Função: Diagnosticando Registros de Representação Semiótica. REFREMAT - Revista Eletrônica de Republicação em Educação Matemática, 5-16.

INSTITUTO BRASILEIRO DE GEOgRAFIA E ESTATÍ́stICA. Panorama das Cidades. [on line]. Citado em 10/07/2019. Disponível em: https://cidades.ibge.gov.br/ INSTITUTO NACIONAL DE ESTUDOS E PESQUISAS EDUCACIONAIS ANISIO TEIXEIRA. Sinopse Estatística da Educação Superior 2017. [on line]. Brasilia: Inep 2018. Citado em 15/07/2019. Disponível em: http://portal.inep.gov.br/web/guest/sinopsesestatisticas-da-educacao-superior

MALTA, I. Linguagem, leitura e matemática in CURY, H. N. Disciplinas matemáticas em cursos superiores: reflexões, relatos, propostas. Porto Alegre: EDIPUCRS, 2004. p.4162.

REZENDE, W. M. (2003). O ensino de cálculo: dificuldades de natureza epistemológica. São Paulo: USP.

SOUZA, K. B; DOMINGUES, E. P. Mapeamento e projeção da demanda por engenheiros por categoria, setor e microrregiões brasileiras. Revista pesquisa e planejamento econômico, v. 44, n. 2, ago. 2014, p, 373 a 404.

SILVA, B. (2009). Componentes do processo de ensino e aprendizagem de cálculo: saber, aluno e professor. Seminário Internacional de Pesquisa em Educação Matemática.

SOARES, E. M. S.; SAUER, L. Z. Um novo olhar sobre a aprendizagem de matemática para a engenharia. In: CURY, H. N. (Org.). Disciplinas matemáticas em cursos superiores: reflexões, relatos, propostas. Porto Alegre: EDIPUCRS, 2004. p. 245-270. 